\title{
Application of Emotional Factors in Optimizing College English Teaching
}

\author{
Lidan $\mathrm{Yu}$ \\ School of Foreign Languages \\ Huanghe Science and Technology College \\ Zhengzhou, China 450005
}

\begin{abstract}
Optimizing English teaching, improving the efficiency of English learning and promoting integrated development of students are the concerns that each English educator pays the most attention to. But when people analyze teaching process, they often focus on cognitive system, while emotional factor, the other important factor, has not received enough attention. This article analyzes the emotional factors in English teaching, starts from the current situations of teaching of teachers and learning of students, carry out emotional teaching in teaching practice and give play to the positive effects of emotional factors in English teaching, hereby promote and optimize college English teaching.
\end{abstract}

Keywords-emotional factor; emotional teaching; college English teaching

\section{INTRODUCTION}

In college English teaching practice, we find many students do not well in English, some students feel "boring" in English class, and some are even on the brink of giving up the curriculum of English. Influenced by exam-orientation education and restricted by college entrance examination, traditional language teaching takes the learning of another language as a pure tool language. Teachers only infuse students with superficial connections and phenomenon of this kind of language on structural style. The stylization and mechanization of foreign language teaching make students in a passive learning state and restrict their initiatives. They even have negative, resistant and learning-weariness emotion. This kind of situation is related to emotional factors to a large extent. Meanwhile, teachers only take teaching as infusion of knowledge and it is difficult for them to experience the fun of work from teaching activities. Teaching activities are bilateral activities between teachers and students, but teachers only pay attention to cognitive factors and make light of emotional factors. There seems to be an invisible wall between teachers and students and they cannot communicate emotion, "so that "emotional illiteracy" appears" (Cheng Xiaotang, 2000), and the effectiveness of English teaching is difficult to be improved.

\section{EMOTIONAL FACTORS IN ENGLISH TEACHING}

Emotional factor is a group of complicated combination of psychological factors, often includes anxiety, restriction, extroverted type and introverted type, self-esteem and motivation and other emotional factors such as transference, patience and adventure, etc. That is to say, the emotional factors in foreign language teaching can be divided into two kinds: the first kind is individual factors of learners, including anxiety, restriction, self-esteem and motivation; the other kind is emotional factors between learners as well as learners and teachers, including transference, communication in class and cross-cultural awareness.

\section{A. Attitude}

Psychologically, attitude refers to the stable behavioral or psychological tendency held by individuals towards human, objects and the surrounding world. Stern (1983) points out three basic attitudes of learners toward foreign language learning: (1) attitudes toward the group of target language and people who say target language; (2) attitudes toward the learning of target language; (3) attitudes toward language and language learning. "Attitude is the first element in second language acquisition" (Ellis, 1985), and learners can be benefited because of positive attitude and damaged by negative attitude. Attitude will not directly influence learning but it will lead to the occurrence of motivation.

\section{B. Motivation}

Psychologically, motivation is understood as: the internal impetus that can promote individual behavior. Motivation is an important emotional factor that affects English learning, the source of language learners' impetus and has connection with the learners' reason or objective to learn foreign languages. Gardner and Lambert (1972) divide motivation of second language learning into integrative motivation and instrumental motivation. The former refers to that learners learn foreign languages in order to integrate into social and cultural groups of target language; the latter is related to utilitarian purpose of learners, such as enter a higher school, obtain employment or promote, etc. Weiner (1986) pointed out that, to attribute failure to internal factors such as character, ability and subjective efforts will distort self image, while positive or negative results caused by external factors such as fortune and difficulties will not influence people's judgment toward their own value. Therefore, in English teaching, it is very important for teachers to know how to guide students to ascribe. 


\section{Self-confidence}

D. Brown (1999) thinks that without enough selfconfidence, any cognitive or emotional effort will not achieve success. With strong self-confidence, students have low degree of language anxiety and relatively strong learning motivation, so they are positive and active in class and can boldly use foreign language to communicate. Therefore, they have more opportunities to practically practice language, and their language proficiency gets improved continuously. Thereby they achieve the desired learning effect and more confidence.

\section{Transference}

Arnold (1999) thinks that transference refers to the process of understanding others considerately. In transference, there is no need to neither give up our own emotional experience nor agree with opinions of others. Transference is nothing but the appreciation of others and their culture, makes people realize their own ways (language, culture and behavior, etc.) are neither the only one nor always the best. The author thinks that giving play to the role of transference in the classroom setting makes for harmonious language learning and communication, such as teachers put more energies into English learning, appreciation of English language will affect students, make them learn English seriously and love English; carrying out group cooperative learning in class can promote students to learn from each other, respect others and learn from advantages of others.

\section{E. Anxiety}

Psychologically, anxiety is a kind of negative emotion, and it refers to that self-esteem and self-confidence of individuals are thwarted because they cannot reach anticipated aim or overcome threats of obstacles, or nervous, scared emotional state formed because of the increase of feeling of failure and sense of guilty. (Zhu Zhixian, 1989)

In the process of language learning, there are three kinds of common language anxieties: classroom anxiety, communication anxiety and examination anxiety. Classroom anxiety mainly shows that in class, learners worry about that their language proficiency and language ability lag behind others and they cannot keep up with the schedule and complete learning tasks. Communication anxiety refers to the anxiety appeared in the fear of real or expected communication with others, and learners are afraid that they cannot correctly use target language to fully make themselves understood. Examination anxiety refers to that students worry about that they cannot perform very well in the examination.

\section{F. Restriction}

Restriction refers to the evasive and recessive behaviors adopted by learners who want to protect themselves because they lack confidence in specific occasion or tasks. In the process of English learning, learners inevitably need to attempt for many times and will make mistakes, which will bring them criticisms and sneers and greatly hit and weaken self image. The more the self image is hit and weakened, the higher the degree of restriction will be. Therefore, students with tender self image will not participate in language activities because they are afraid to make mistakes, which obviously go against English teaching. These psychological barriers built by them will have no promoting effects on language learning. If we want to learn language well, we must get rid of them.

Zankov (1980) points out definitely in Teachers' Talk that: in terms of the effects of educational work, one of the important aspects is the relationship between teachers and students. Therefore, the emotion between teachers and students will finally affect the effects of teaching and education through direct actions of their interaction activities and relationships. Starting from the current situations of teachers' teaching and students' learning, it is easy to achieve the result that it is quite necessary and extremely urgent to advocate emotional teaching in foreign language teaching.

\section{LEVEL OF TEACHING OF TEACHERS}

\section{A. Emotions of Teachers, Set Examples with Their Own Behaviors Instead Of Expounding Knowledge Mechanically}

Confucius says in Records of Education that, "People who are on intimate terms with their teachers will believe the truth said by teachers", which refers to that only when a person likes and respects the teacher will he believe and learn the knowledge and truth imparted by the teacher. Therefore, I do everything I can to become students' good teacher and helpful friend through improving my own quality and culture in aspects such as professional knowledge, academic research and manners and appearance to reach the effects of influencing students imperceptibly.

1) Professional scholarly attainments, use knowledge to affect students. Teachers should continuously strengthen the culture of English professional knowledge and make efforts to shape impeccable self image and power of personality. Personality traits of teachers such as professional dedication, self-awareness, and individual style and frustration tolerances will have strong influences on students. Quality and demonstration effects of teachers are the premises for students to learn English well. Set examples for students, use the transfer of emotion, move positive emotions of students toward teachers to the contents taught by teachers and then motivate their impetus to do their best to learn English.

2) Humorous and passionate, use words to make students be willing to listen to the teacher. Students say that, "we hope that teachers can say humorous words. When we appreciate teachers' rich expressions and humorous languages, we will be certain to actively concentrate more attention on classroom learning." True humor can bring an understanding smile, laughter and happiness, which show teachers' teaching level as well as embody the wisdom of teaching.

3) Demure appearance, use postures to influence students. When stepping into the classroom, teachers should: 
come to the door of the classroom in high spirits or wait for having class in the classroom in one or two minutes ahead of time. The style, color and size of dressing should be harmonious and unified with individuality. In class, the teacher should have demure appearance, high spirits and be passionate, thus emotions of students will be affected and motivated.

\section{B. Excavate Teaching Materials and Penetrate Emotions}

Except for English textbook and its matched supplementary materials, we also introduce sounds, texts, images and other foreign language teaching resources received through other channels, and absorb the quintessence and make good use of them. For example: English resources come from daily life such as road signs, signboards, direction boards, greeting cards, advertisements and product specification, and can directly or indirectly serve as resources of teaching. Some English information resources can also become teaching resources of middle school English after they are modified slightly; English resources that come from films, videos and English movies with original sounds provide us with environments to apply language and make us have the feelings of "be personally on the scene" for the use of language; resources coming from English popular songs add fun to our class.

\section{Teach with Emotions, Integrate Emotions with Knowledge}

1)Emotional aims. Use students “can do something” to specifically describe requirements at all levels. Teachers can choose action verbs to describe emotional teaching targets in classroom. Meanwhile, the location of emotional teaching targets must correspond to reality and cannot exaggerate the effects that a lesson can reach: taking students as the principle part, the teaching process should center on the objectives to design and disconnection should not appear between processes.

2)Atmosphere before class. When students learn in happy and harmonious classroom atmosphere, their thoughts will become extraordinarily quick with more open consciousness, which can reduce the negative effects produced by inner pressure and speed up the pace to master knowledge. Teachers will also better give play to their teaching level and improve the quality of teaching in relaxed atmosphere of teaching and learning. Before class, play some English songs, create relaxed and amused atmosphere of English and it is better to choose songs that have close relationships with teaching contents. At the same time, teachers can seize the opportunity to let students listen to the music and fill in the lyrics, learn to sing English songs, enhance their interests in learning English and create opportunities for students to use English.

3)Ingeniously design the lead-in. It is of vital importance to elaborately design the lead-in. In this link, teachers should present the theme of text to students, at the same time, arouse their interests and strike a chord, let them have strong desires to participate in, and also can draw forth core vocabularies in the discourse in the process of lead-in. It is feasible to use pictures in the text to lead in: Before students begin to read, the teacher use some pictures to guide students to think about contents of the text, predict main idea of the text and use this to lead in the topic. The teacher also can use multimedia courseware to lead in. Multimedia courseware is visualized tool to lead in, and it can greatly attract attention of students and has large amounts of information.

\section{LEVEL OF LEARNING OF STUDENTS}

\section{A. Elaborately Care for Students' Emotions}

In One Hundred Advice for Teachers, Sukhomlinskii (1981) assimilates students' emotions as land and students' intelligence as seeds. He says, "Only concerning the seeds and forgetting to cultivate the land is equal to scatter seeds to feed sparrows". He also says that, "Learning in school is not blankly pack knowledge in one mind into another mind but the contacts that happen between teachers' mind and students' mind all the time". Starting from aspects such as motivate students' motivation, correct their attitudes toward English learning, develop there interest in learning, reinforce their confidence, care for their self-esteem, harden their wills of English learning and adjust and control anxious emotions and reduce the restrictions, give play to positive role of emotional factors in the process of teaching and promote the improvements of students' emotional quality. In order to stimulate students' motivation, motivation is the internal motivation factors and strengths to stimulate people to act. No matter integrative motivation or instrumental motivation, they all play significant roles in promoting foreign language learning.

Many students complain that they cannot remember English vocabularies and always feel frustrated about the words forgotten by them. They are in a negative psychological state and cause psychological barriers for themselves. Therefore, in teaching process, I teach students to learn reverse thinking that they should not calculate how many words forgotten by them but calculate how many words remembered by them today in turn. In this way, students will feel very confident. We need to care for selfesteem of students. William James, the father of American psychology, the famous psychologist, has a famous saying,

"The most profound principle of humanity is to hope others to appreciate themselves". James also finds that a man who is not stimulated can only give play to twenty to thirty percent of his ability, while after he is stimulated, his ability is three to four times of the ability before stimulation. Therefore, in the process of learning, the existence of stimulation is of vital importance. All students need continuous stimulation.

\section{B. Shorten the Distance Between Hearts of Teachers and Students, Create Harmonious Atmosphere}

Students think that teachers and students have little communication after class and emotional exchange lacks between teachers and students. As an English teacher, I have actively known about their families, learning and hobbies, etc. Trust students and have consciousness of transpositional thinking, then we can achieve the effect of emotional 
resonance with students. As the saying goes that to see is to believe. But in reality, to see is not always to believe. On one occasion, I assign students to do exercises in class and allow them to look up words in the dictionary. I get a glimpse of that a student is using mobile phone to "send short messages" by chance, but in order to not to destroy classroom atmosphere, I have nothing to do but endure. After class, I query her with the tone of little blame that how she can use mobile phone to "send short messages" in class, "Teacher, I did not! I used the mobile phone to look up the words." Unexpectedly, she excuses herself with a face of innocence. Later I know that what she says is true. So at this time, I rejoice that I use gentle attitude to dissolve the misunderstanding between teacher and student.

\section{Guide with Learning Methods and Make Students "Do Well in Learning"}

Guiding students to understand, and form and apply their personalized learning strategies not only can develop their abilities to learn individually and independently and improve their learning results, but also helps to lay good foundation for their lifelong learning and development. Teachers cultivate students about learning strategies mainly through penetration in daily teaching process and using subtle way to realize. These learning strategies include vocabulary learning strategy, grammar learning strategy, listening strategy of English learning, learning strategies of spoken English, reading strategy of English learning and writing strategy of English learning, etc. Teachers cultivate learning strategies, which penetrates in each link of teaching. For example, before assigning writing tasks for students, the teacher should give instructions at first and should not feel troublesome. It is necessary to insist in the long term until internalizing these learning strategies as self-conscious behaviors of students.

\section{CONCLUSION}

Using emotional factors to optimize college English teaching is feasible. Carrying out emotional teaching can change the idea that attaching importance to cognition and pay less attention to emotion, and implement the important idea of "people first"; Mobilizing and inspiring positive emotional factors of students can improve the efficiency of English teaching; cultivating English learning emotion helps to develop cognitive levels and emotion qualities of students.

\section{REFERENCES}

[1] Babanski, 1985. Optimization of Education Process [M], Beijing: Education and Science Press

[2] Bloom, 1986. Taxonomy of Educational Objectives [M], Shanghai: East China Normal University Press

[3] Bruner, 1989. Selections of Bruner's Education Works [M], Beijing: People's Education Press

[4] Cai Yuanpei, 1987. Cai Yuanpei's Education Analects [M], Changsha: Hunan Education Press

[5] Chen Heqin, 1949. Opinions on Education [M], Shanghai: Shanghai Huahua Bookstore
[6] Cheng Xiaotang 2000, Introduction to Emotion and Language Learning, Affect in Language Learning, Beijing: Foreign Language Teaching and Research Press 